\title{
Od Mehike do Brazilije, od starodavne Kitajske do novega konfucianizma: sinološke študije v Latinski Ameriki
}

Ključne besede: Latinska Amerika, sinologija, konfucianizem, El Colegio de México, Estudios de Asia y África, Chen Yong, André Bueno

DOI: $10.4312 /$ ars.10.1.220-242

»Če hodim kot tretji poleg dveh, imam zagotovo učitelja.

Konfucij, Pogovori, IV, 22

\section{Uvod}

Latinska Amerika in Kitajska sta kulturni okolji, med katerima se kljub medsebojnemu slabemu poznavanju zaradi odsotnosti zgodovinskih stikov in geografske oddaljenosti v 20. stoletju začenjajo vzpostavljati določene povezave, tudi zaradi naraščajočega priseljevanja kitajskih delavcev v 20. letih, najprej v Srednjo Ameriko in kasneje v druge latinskoameriške države (Chou, 2002, 16). V zadnjih desetletjih, ko Vzhodna Azija postaja pomemben igralec na gospodarskem in političnem prizorišču, narašča zanimanje za krepitev gospodarsko-političnih odnosov, o čemer pričajo ustanovitve številnih združenj in centrov, organizacije mednarodnih konferenc in raznovrstne publikacije, ${ }^{1}$ ki se osredotočajo na družbenopolitične in gospodarske teme, medtem ko se na raziskovalno-znanstvenem področju večji premiki začnejo dogajati šele v 21. stoletju (razen nekaterih izjem, ki jih bomo opisali v nadaljevanju), predvsem po odprtju več kot petindvajsetih Konfucijevih inštitutov ${ }^{2}$ na latinskoameriških tleh (prvi je bil odprt leta 2006 v mehiškem glavnem mestu).

V tem kratkem pregledu bomo poskušali zarisati splošni okvir začetkov in razvoja sinoloških študij na geografsko, politično in kulturno zelo raznolikem področju

1 Na primer Creutzfeldt (2012), Chen Mok in dr. (2013) ter vse več strokovnih člankov, ki raziskujejo družbeno-politične odnose in povezave med Latinsko Ameriko in Kitajsko (npr. Johnson, Lin, 2015).

2 Trenutno se nahajajo v desetih državah Latinske Amerike: Argentina, Bolivija, Brazilija, Čile, Kolumbija, Kostarika, Kuba, Ekvador, Mehika in Peru. 
Latinske Amerike ter izpostaviti osrednje aktualne vidike in tendence. Natančneje bomo predstavili situacijo $\mathrm{v}$ Mehiki, državi $\mathrm{z}$ najdaljšo sinološko tradicijo, ter $\mathrm{v}$ Braziliji, kjer je sinologija še na samem začetku, predvsem skozi prizmo raziskav dveh sinologov, Chen Yonga (El Colegio de México) in Andréja Buena (Universidade do Estado Rio de Janeiro). ${ }^{3}$

\section{Vzpostavljanje odnosov in začetki sinologije}

Latinskoameriške države imajo s Kitajsko vsaka svojevrsten odnos, zato ni presenetljivo, da se, na primer, na Kubi že več desetletij izobražujejo predvsem prevajalci, da je edino v Mehiki mogoč doktorski študij sinologije ali da ima Čile zaradi strateške povezave $s$ Pacifikom devetkrat več štipendistov na Kitajskem kot Argentina. Kar pa povezuje tako špansko govoreče države Latinske Amerike kot Brazilijo, je odsotnost daljše sinološke tradicije. ${ }^{4}$ Vidnejši univerzitetni programi in pomembnejši centri, ki vključujejo programe azijskih in afriških študij, so v Argentini, Braziliji, Čilu, Kolumbiji, Kostariki, ${ }^{5}$ na Kubi, v Mehiki, ${ }^{6}$ Peruju in Venezueli. Poleg tega je osrednji poudarek navadno predvsem na proučevanju mednarodnih odnosov, gospodarstva, politike in modernega jezika. Kot rečeno, pri širjenju zanimanja za kitajski jezik in kulturo v Latinski Ameriki igrajo pomembno vlogo Konfucijevi inštituti, ki pogosto delujejo v okviru univerz in drugih izobraževalnih središč. Maja 2014 so se povezali v regionalni center, t. i. Centro regional de Institutos Confucio para América Latina, CRICAL. Na njihovi spletni strani lahko preberemo, da je največ, osem inštitutov v Braziliji, sledi ji Mehika s petimi, v Peruju in Kolumbiji so

3 V prihodnje bi vsekakor veljalo raziskati položaj sinologije tudi v ostalih državah Latinske Amerike.

4 Velja omeniti, da ima na Kitajskem zanimanje za Latinsko Ameriko daljšo tradicijo (Chen Mok in dr., 2013), o čemer priča dejstvo, da je bil v Pekingu že leta 1961 ustanovljen Inštitut za Latinsko Ameriko (Instituto de América Latina; angleško ime Institute of Latin American Studies, ILAS), ki od leta 1981 deluje pod okriljem Kitajske akademije za družbene vede (Chinese Academy of Social Sciences, CASS). Na omenjenem inštitutu od leta 1979 izdajajo revijo Revista de Estudios Latinamericanos, ki je še danes edina revija na Kitajskem, ki se posveča izključno latinskoameriškim študijam (Ilas.cass. cs). Omeniti velja še ustanovitev Kitajskega združenja za latinskoameriške študije (Asociación China de Estudios Latinoamericanos, ACEL) leta 1984 ter vpeljavo podiplomskih študijskih programov za latinskoameriške študije na univerzah v Pekingu, Nankaiu, Fudanu in Hubeiu (Shixue, 2004, 277).

5 Leta 1973 je v takrat še Estudios Orientales izšel zanimiv članek z naslovom »Orientalske študije na Univerzi v Kostariki« (Los estudios orientales en la Universidad de Costa Rica), kjer preberemo, da je na Oddelku za geografijo in zgodovino že leta 1969 obstajal predmet »Kulturna zgodovina Kitajske«, na Oddelku za filozofijo pa predmet »Uvod v budizem«(Chen A. Espinosa, 1973, 88).

6 Omeniti velja štiri pomembnejše univerzitetne programe, ki so neposredno povezani s kitajskimi študijami: najbolj znan je gotovo Center za azijske in afriške študije (Centro de estudios de Asia y África), ki je bil ustanovljen v Mehiki leta 1964 v okviru El Colegio de México (predstavimo ga v poglavju 2.1), drugo najstarejše središče pa je bilo leta 1967 ustanovljeno na Univerzi v Salvadorju kot Šola za orientalske študije (La Escuela de Estudios Orientales). Pred desetimi leti so na Avtonomni univerzi v Mehiki (Universidad Autónoma de México) ustanovili Center za študije Kitajska-Mehika (Centro de Estudios China-México), ki mu je dve leti kasneje sledil še Center za študije KitajskaVeracruz (Centro de Estudios China-Veracruz) v mehiškem Veracruzu. 
po štirje, na Kubi trije, v ostalih državah pa po dva ali eden. ${ }^{7} \mathrm{~V}$ zadnjem desetletju so prav ti inštituti omogočili sodelovanje in vzpostavitev partnerstva med različnimi državnimi in zasebnimi institucijami. Pod njihovim okriljem se organizirajo številna mednarodna srečanja, ki pripomorejo k razvoju zanimanja za sinologijo v Latinski Ameriki. Še posebej so v tej smeri aktivni inštituti v državah, kjer jih je manj. Konfucijev inštitut na Univerzi v Kostariki na primer od leta 2008 organizira mednarodne simpozije, ki si prizadevajo kitajske študije osvetliti z latinskoameriške perspektive. Rezultat enega izmed njih je zanimiva publikacija iz leta $2013 \mathrm{z}$ naslovom Študije o Kitajski iz Latinske Amerike. Geopolitika, religija in priseljevanje (Chen Mok in dr., Estudios sobre China desde Latinoamérica. Geopolitica, religión e inmigración), ki se osredotoča na zgodovinske, geopolitične, mednarodne in gospodarske vidike Kitajske v luči povezav z Latinsko Ameriko. Zbornik je tako obvezno branje za vse zgodovinarje in tiste, ki se ukvarjajo $\mathrm{z}$ mednarodnimi odnosi. Vidnejšo vlogo ima tudi Konfucijev inštitut v Argentini. Od leta 2009 deluje v okviru Univerze Nacional de La Plata in njenega Centra za kitajske študije ( $E l$ centro de estudios chinos, CeChino), ki je bil ustanovljen leta 1996 in obsega študij prava, politologije, zgodovine, kulture, kitajskega jezika in mednarodnih odnosov. Novembra 2011 sta omenjena inštituta organizirala odmeven dogodek posebnega pomena za latinskoameriško sinologijo: prvi regionalni latinskoameriški kongres o kitajskih študijah (I Congreso Latinoamericano de Estudios Chinos), ki je združil več kot sto strokovnjakov in raziskovalcev iz desetih držav Latinske Amerike. Ti so s svojimi prispevki razmišljali o jeziku in kulturi (tudi o filologiji), družbi, gospodarstvu in politiki. Konfucijev inštitut v Kolumbiji, ki deluje na univerzi Los Andes, pa je leta 2014 organiziral prvi mednarodni kongres Dialogi s Kitajsko: nov prostor za kitajske študije (Diálogos con China; un nuevo espacio para los estudios chinos), ki se je osredotočil predvsem na kitajsko književnost, na prve stike med Zahodom in Kitajsko ter na sodobno kitajsko zgodovino.

Dejstvo je, da so se povezave med Latinsko Ameriko in Kitajsko močno okrepile $\mathrm{v}$ zadnjem desetletju, ustanavljajo se različni centri, včasih tudi v okviru univerz, ki pa v večini primerov še vedno izhajajo iz gospodarskega ali političnega temelja, ${ }^{8}$ čeprav se vezi krepijo tudi na kulturnem, umetniškem in izobraževalnem področju. $\mathrm{V}$ zadnjih letih prevladuje težnja po združitvi špansko in portugalsko govorečega prostora, tako da se latinskoameriške države v skupne okvire povezujejo s Portugalsko in Španijo, predvsem na pobudo slednje. Leta 2007 je bila zato s podporo španskega

\footnotetext{
7 http://www.crical.cl/institutos/ [6.3. 2016].

8 Leta 2011 je bil, na primer, na Univerzi Andrés Bello v Chilu ustanovljen Centro de Estudios Latinoamericanos Sobre China (CELC), ki se osredotoča predvsem na politično-gospodarske in ne akademsko-raziskovalne povezave, čeprav uradno deluje pod okriljem univerze.
} 
Ministrstva za izobraževanje in znanost ustanovljena t. i. Iberoamerišk $a^{9}$ raziskovalna mreža za vzhodnoazijske študije (Red Iberoamericana de Investigación en Estudios de Asia Oriental, REDIAO ${ }^{10}$ s sedežem na univerzi Autónoma v Madridu. Njen osrednji namen je spodbujanje raziskav o Vzhodni Aziji v španskem in portugalskem jeziku ter povezovanje raziskovalcev, centrov in združenj, ki se ukvarjajo s to tematiko. V okviru mreže je leta 2009 začela izhajati revija za vzhodnoazijske študije (Revista Iberoamericana de Estudios de Asia Oriental, RIEAO), kjer velja omeniti študijo, objavljeno v prvi številki, "Analiza daoistične intuicije pri mislecu Mou Zongsanu“ (Análisis de la intuición taoísta en el pensador chino Mou Zongsan), ${ }^{11} \mathrm{v}$ kateri sicer francoski sinolog Jean-Claude Pastor Ferrer, ki se ukvarja tudi z modernim konfucijanstvom, raziskuje koncept intuicije v zgodovini kitajske filozofije.

Podobno je bil od leta 2012 do danes dvakrat organiziran t. i. Iberoameriški kongres za kitajske študije (Congreso Iberoamericano de Estudios Chinos) v organizaciji Konfucijevih inštitutov v Argentini in Španiji ter v sodelovanju z argentinsko univerzo Universidad Nacional de La Plata in španskima univerzama, Univerzo v Barceloni ter Univerzo v Valenciji.

V okviru povezovanja med latinskoameriškimi univerzami velja posebej izpostaviti prizadevanja Združenja latinskoameriških in karibskih univerz (Unión de Universidades de América Latina y el Caribe, UDUAL) ter Centra za kitajsko-mehiške študije ${ }^{12}$ (el Centro de Estudios China-México, CECHIMEX) na Ekonomski fakulteti Nacionalne avtonomne univerze v Mehiki (Universidad Nacional Autónoma de México, UNAM). Ti so maja 2012 organizirali prvi mednarodni seminar z naslovom »Latinska Amerika, Karibi in Kitajska: okoliščine in izzivi v 21. stoletju (América Latina y el Caribe y China: condiciones y retos en el siglo XXI). Na njem je sodelovalo več kot sto strokovnjakov, akademikov in poslovnežev, ki so $\mathrm{v}$ svojih prispevkih predstavili raziskave znotraj štirih temeljnih področij: gospodarstvo in trgovina, politični odnosi, okolje in naravni viri ter zgodovina, kultura in učenje kitajščine. Seminar je bil tudi povod za ustanovitev Akademske mreže Latinske Amerike, Karibov in Kitajske ( $L a$ Red

9 Izraz iberoameriški (iberoamericano) je redkejši v slovenskem jezikovnem okolju, kjer se uporablja predvsem splošnejši latinskoameriški. Ta izraz je pogostejši in tudi edini, ki ga najdemo v SSKJ in Slovenskem pravopisu. Izraz iberoameriški je dokumentiran v besedilnih korpusih, npr. Gigafida [1. 3. 2016]. V špansko in portugalsko govorečem prostoru je razdelitev natančnejša: hispanoamericano (hispanoameriški) se nanaša na špansko govoreče države, iberoamericano (iberoameriški) na špansko in portugalsko govoreče države ter latinoamericano (latinskoameriški) na države Srednje in Južne Amerike, kjer je uradni jezik eden izmed romanskih jezikov (torej tudi francoščina).

10 http://rediao.org/site/index.php [1.3. 2016].

11 RIEAO, 2008, 11-21.

12 Sicer s temeljno usmeritvijo predvsem v gospodarsko-politične odnose med Kitajsko in Mehiko. 
Académica de América Latina y el Caribe sobre China, ACEL), ${ }^{13}$ organizacije, ki skuša zapolniti naraščajočo potrebo po akademskih in raziskovalnih združenjih v Latinski Ameriki, ki bi se ukvarjala s povezavami s Kitajsko in tako presegala okvire nacionalnih institucij. Mreža je mednarodni seminar z istim naslovom organizirala tudi leta 2014, v pripravi pa je tretji, ki bo maja 2016. V okviru akademske mreže izhajajo raznolike publikacije, leta 2015 so izdali monografijo o zgodovini, kulturi in učenju kitajščine (Historia, cultura y aprendizaje del chino). Uredila jo je znana latinskoameriška sinologinja Liljana Arsovska, sicer profesorica za kitajski jezik na El Colegio de México, ki je doktorirala v Pekingu. Izmed sedemnajstih prispevkov se eden neposredno ukvarja s Konfucijem, v katerem se mehiška filozofinja in ekonomistka Balboa Reyna posveča konceptu ritualizacije pri Konfuciju (Arsovska, 2015, 5-6). Ne nazadnje je treba omeniti tudi pred kratkim ustanovljeno Iberoameriško sinološko mrežo (Red Iberoamericana de Sinología, RibSi), ki združuje najrazličnejše strokovnjake za Kitajsko iz desetih latinskoameriških držav ter Španije in Portugalske.

V edini portugalsko govoreči državi Latinske Amerike, Braziliji, imajo sinološke študije krajšo tradicijo, čeprav se v zadnjem desetletju situacija hitro spreminja, tudi zaradi prihoda sedmih Konfucijevih inštitutov. Brazilci sicer v Kitajski vidijo dobro gospodarsko-politično partnerico, medtem ko sta kitajska kultura in zgodovina za Brazilce še vedno nenavadni in eksotični (Bueno, 2015, 114). Dejstvo je, da na brazilskih univerzah (še) ne poznajo kitajske misli, kar pa preseneča, je, da tudi na osrednji brazilski univerzi v Rio de Janeiru (Universidade Federal de Rio de Janeiro) v sklopu Oddelka za orientalske in slovanske jezike še danes nimajo sekcije za sinologijo ali vsaj za kitajski jezik (čeprav je na spletni strani oddelka zapisano, da je v pripravi), ${ }^{14}$ medtem ko od leta 1969 deluje sekcija za arabske študije, od leta 1971 sekcija za hebrejski jezik in književnost, od leta 1979 sekcija za japonski jezik in od leta 1968 sekcija za ruski jezik. Izven akademskega okolja velja v Braziliji omeniti Inštitut za brazilsko-kitajske študije ${ }^{15}$ (Instituto de Estudos Brasil-China, IBRACH), neprofitno organizacijo, ki združuje različne interesne skupine, katerih delo je povezano s Kitajsko. Med njimi so tako univerzitetni raziskovalci kot politiki in gospodarstveniki. Inštitut sodeluje $\mathrm{z}$ več univerzami in raziskovalnimi centri $\mathrm{v}$ Braziliji in tujini, pri izvedbi raziskovalnih programov ( $v$ večji meri gospodarskopolitične tematike) pa sodeluje $\mathrm{z}$ Univerzo $\mathrm{v}$ Tsinghua in Federalno univerzo $\mathrm{v}$ Rio de Janeiru.

13 http://www.redalc-china.org/ [6. 3. 2016].

14 http://www.orientaiseeslavas.letras.ufrj.br/?page_id=176 [1.3. 2016].

http://www.ibrach.org/ [1.3. 2016]. 


\subsection{El Colegio de México in revija Estudios de Asia y Árica}

Dejstvo je, da ima najdaljšo tradicijo sinoloških študij v Latinski Ameriki Mehika, kjer je bila v 60. letih prejšnjega stoletja na eni najuglednejših raziskovalnih in visokošolsko-izobraževalnih institucij v špansko govorečih državah, El Colegio de México (COLMEX), ${ }^{16}$ ustanovljena sekcija za orientalske študije. Gre za javno univerzitetno institucijo, ki jo sestavlja sedem študijsko-raziskovalnih centrov, ki pokrivajo področja zgodovine, jezikoslovja in književnosti, mednarodnih odnosov, azijskih in afriških študij, gospodarstva, sociologije in demografsko-okoljskih študij. Nastanek El Colegio de México sega v oktober 1940, ko nasledi institucijo La Casa de España, ustanovljeno leta 1938 na pobudo takratnega mehiškega predsednika Lázara Cárdenasa kot pribežališče za ugledne španske znanstvenike, akademike in umetnike pred državljansko vojno. Med soustanovitelji El Colegio de México sta bila tudi mehiški pesnik in pisatelj Alfonso Reyes ter zgodovinar in sociolog Daniel Cosío Villegas. Po slednjem se imenuje univerzitetna knjižnica, ki ima več kot 650.000 bibliografskih enot (Lida in dr., 2000).

S podporo UNESCO-vega projekta Proyecto Mayor Oriente-Occidente, katerega glavni namen je bil vzpostavitev mostov med Vzhodom in Zahodom ter širjenje afroazijskih študij v Latinski Ameriki, se je torej v okviru Centra za mednarodne študije (Centro de Estudios Internacionales) na El Colegio de México leta 1960 oblikovala Sekcija za orientalske študije (Sección de Estudios Orientales), ki se je osem let kasneje preoblikovala v Center za Orientalske študije (Centro de Estudios Orientales), leta 1976 pa preimenovala v Center za azijske in afriške študije (Centro de Estudios de Asia y África, CEAA),${ }^{17}$ kot se imenuje še danes. Center je v več kot petdesetih letih delovanja oblikoval svojevrsten latinskoameriški pogled na Azijo in Afriko, predvsem pa spodbujal zanimanje za zgodovino, kulturo, politiko, gospodarstvo in jezike teh držav. El Colegio de México je še vedno edino središče v Latinski Ameriki, kjer je možen doktorski študij sinologije. Na Centru za orientalske študije je zaposlenih 28 profesorjev, od tega sedem sinologov, ki so vsi izvrstni strokovnjaki z mednarodnim ugledom. ${ }^{18}$ Med njimi je tudi diplomantka prve generacije študentov za področje sinologije, danes ugledna mehiška sinologinja Flora Botton Beja, specialistka za kitajsko zgodovino in filozofijo. Velja za ustanoviteljico akademskih sinoloških študij

16 Angleško The College of Mexico. Zaradi specifične narave institucije, ki je bližje slovenskemu konceptu univerze kot kolidža, povsem ustrezna pa ni nobena od različic, smo se v tej študiji odločili za rabo izvirnega imena.

17 Med drugim gre tudi za posledico prizadevanja za večjo korektnost poimenovanja, saj naj bi bil termin »orientalski« preveč evropocentričen (http://ceaa.colmex.mx/ceaa/historia [6. 3. 2016]).

$18 \mathrm{Z}$ njimi sodeluje tudi priznani strokovnjak za budizem Luis Óscar Gomez, častni profesor univerze v Michiganu. 
v iberoameriških državah sploh, prav tako pa je sodelovala pri izobraževanju številnih pomembnih sodobnih latinskoameriških sinologov. Je avtorica in soavtorica več monografskih publikacij o kitajski zgodovini (npr. China. Su historia y cultura hasta 1800 iz leta 2008, Historia mínima de China, ki je izšla leta 2010), poglavij v monografijah in enciklopedijah ter številnih znanstvenih člankov v latinskoameriških in evropskih revijah (za podroben seznam glej Cornejo, 2012). Tu naj izpostavimo predvsem tiste, ki imajo neposredno povezavo s Konfucijem in konfucijanstvom: poglavje $\mathrm{v}$ monografski publikaciji o teoriji in zgodovini religij $\mathrm{z}$ naslovom »Konfucianizem in budizem na Kitajskem; med vero in razumom« (Confucianismo y budismo en China: entre la fe y la razón), ${ }^{19}$ znanstveni članki »Konfucianizem v azijskih gospodarskih čudežih" (El confucianismo en los milagros económicos asiáticos) ${ }^{20}$ in "Konfucijevi pogovori: slava ali breme kitajske tradicije« (Las Analectas de Confucio: Gloria o lastre de la tradición china). ${ }^{21} \mathrm{Z}$ objavljanjem sinoloških študij v različnih revijah s sicer širšo tematiko (družbene vede, zgodovina, humanistika) ${ }^{22}$ je pomembno prispevala k širitvi in dostopnosti sinologije v širšem okolju. Z objavami v prestižni španski reviji Revista de Occidente ${ }^{23}$ (ki jo je leta 1923 ustanovil španski intelektualec in filozof José Ortega y Gasset) pa je nedvomno pripomogla k širitvi ugleda latinskoameriške sinologije tudi v Evropi.

El Colegio de México je povezan še z eno pomembno prelomnico v razvoju azijskih in afriških študij v Mehiki ter nasploh v Latinski Ameriki v 70. letih prejšnjega stoletja: to je bila organizacija 30. mednarodnega kongresa za humanistične študije Azije in Severne Afrike (el Trigésimo Congreso Internacional de Ciencias Humanas de Asia y África del Norte), ki je leta 1976 potekal pod okriljem takratnega mehiškega predsednika Luisa Echeverrie v glavnem mestu Mehike. Šlo je za prvi kongres takega obsega na latinskoameriških tleh in El Colegio de México je bil glavni organizator dogodka. Srečalo se je več kot 2000 strokovnjakov s 500 univerz iz 65 držav, kar je po koncu kongresa pomenilo ogromno dragocenega materiala. Rezultat je bil neprecenljiva zbirka gradiva za proučevanje Azije in Afrike, ki hkrati odraža takratne najpomembnejše tendence.

Omenjeni kongres je bil tudi povod za ustanovitev Latinskoameriškega združenja za azijske in afriške študije (Asociación Latinoamericana de Estudios de Asia y África,

19 Valverde Valdés, M., Velasco Bengoa, M. R., Teoría e Historia de las Religiones, México 2010, str. 159-179.

20 Revista Iztapalapa, 42, 1997, str. 117-134.

21 Facultat d'Humanitats, Barcelona 1994.

22 Na primer Revista de la Universidad de México, Estudios demográficos y urbanos (Mehika), Revista de Estudios Budistas (Mehika), Revista Iztapalapa (Mehika), Temas de África y Asia (Buenos Aires, Argentina), Revista de Occidente (Španija), Anuario Asia-Pacífico (Španija).

http://www.ortegaygasset.edu/publicaciones/revistadeoccidente [1. 3. 2016]. 
ALADAA $)^{24}$ s sedežem na Centru za azijske in afriške študije na El Colegio de México, ki združuje študente, učitelje, raziskovalce in druge zainteresirane. Glavni namen združenja je izmenjava informacij in akademskih izkušenj med člani, sodelovanje $\mathrm{z}$ visokošolskimi središči v Latinski Ameriki ter širjenje antičnih in modernih študij ter ostalih znanj, ki pripomorejo k boljšemu poznavanju Azije in Afrike v Latinski Ameriki. Od leta 1976 vsaki dve leti organizirajo mednarodne kongrese v različnih latinskoameriških državah (Mehika, Kolumbija, Brazilija, Venezuela, Argentina, Kuba). Združenje letos praznuje 40. obletnico delovanja, ki so jo obeležili s petnajstim mednarodnim kongresom v Čilu.

Zaenkrat v Latinski Ameriki ne obstaja nobena znanstvena revija, ki bi se posvečala samo kitajskim študijam, jih je pa kar nekaj, ki vključujejo azijsko in afriško področje, najpomembnejša je brez dvoma Estudios de Asia y África, ki jo izdaja El Colegio de México. Omeniti velja tudi argentinsko revijo Temas de África y Asia, ki jo, sicer neredno, izdaja Univerza v Buenos Airesu. V njej je sicer večji poudarek na afriških študijah, podobno kot v brazilski reviji Estudos Afro-asiáticos, ki je pred kratkim začela izhajati v okviru centra z istim imenom (Centro de Estudos Afro-Asiáticos, CEAA) na univerzi Cândido Mendes v Rio de Janeiru.

Pod okriljem El Colegio de México poleg sedmih znanstvenih periodičnih publikacij, ki izhajajo vsako leto $\mathrm{v}$ okviru sedmih raziskovalno-študijskih centrov, tudi sicer izhaja več mednarodnih znanstvenih publikacij in revij, letno izide med 80 in 90 novih naslovov. ${ }^{25}$ Med njimi je s področjema sinologije in konfucianizma neposredno povezana znanstvena revija Azijske in afriške študije (Estudios de Asia y África, 1966), ${ }^{26} \mathrm{ki}$ je bistvenega pomena za špansko govoreče sinologe, saj je edina akademska interdisciplinarna revija $\mathrm{v}$ španskem jeziku, ki se osredotoča na kulturo, antropologijo, zgodovino, književnost, družbene, gospodarske in politične vede ter regionalne študije azijskih in afriških držav. ${ }^{27}$ Izhajati je začela leta 1966 pod imenom Orientalske študije (Estudios Orientales), leta 1975 se je preimenovala v Estudios de Asia y África, ne da bi to vplivalo na oštevilčenje letnikov. Izhaja trikrat na leto. Objavlja

$24 \mathrm{http} / / /$ ceaa.colmex.mx/aladaa/ [1.3. 2016].

25 Na spletu je dostopen katalog vseh knjižnih publikacij od leta 1938 do 2011: http://libros.colmex.mx/ index.php/catalogo-1938-2011 [1.3.2016].

26 http://revistas.colmex.mx/sobre-estudios-de-asia-y-africa/ [1. 3. 2016].

27 Omeniti je treba, da se ji bo leta 2016 sicer v Španiji pridružila nova znanstvena revija Sinología Hispánica, ki se bo posvečala izključno sinološkim študijam ter povezavam med sinologijo in hispanistiko. Izhajala bo v okviru Konfucijevega inštituta na Univerzi v Leonu. V Španiji prvi izbirni predmeti o kitajski civilizaciji in kulturi segajo v leto 1978 (Univerza v Granadi), leta 1989 je bil ustanovljen Center za kitajske študije (Centro de Estudios Chinos) na avtonomni univerzi v Barceloni, leta 1992 pa na avtonomni univerzi v Madridu Center za vzhodnoazijske študije (Centro de Estudios de Asia Oriental). V 21. stoletju se tako v Španiji govori o drugi generaciji sinologov, ki nadaljuje tradicijo univerz v Granadi, Barceloni in Madridu (Herrera Feligreras, 2008, 260). 
izvirne znanstvene članke hispanoameriških, azijskih, afriških, evropskih in ameriških raziskovalcev, prevode člankov in besedil iz azijskih in afriških jezikov, informativne članke o aktualnih temah ter kritične diskusije in recenzije relevantnih publikacij.

\section{Konfucij in konfucijanske študije v Latinski Ameriki}

\section{1 Kratek pregled najpomembnejših prevodov v 20. stoletju}

Kriterij v pričujoči raziskavi je izid prevoda znotraj geografskega območja Latinske Amerike, kajti če govorimo o prevodih Konfucijevih del na splošno v španski ${ }^{28}$ in portugalski jezik, moramo začeti v poznem 16. stoletju, ko se s prihodom jezuitov na Kitajsko začne živahno obdobje prevajanja iz kitajščine in v kitajščino. Za našo študijo je pomembno omeniti deli dveh dominikanskih misijonarjev: Juan Cobo je leta 1592 zaslužen za prvi prevod kitajskega dela v katerikoli »jezik Zahoda« sploh, v tem primeru v španščino; gre za delo Beng Sim Po Cam ali bogato ogledalo dobrega srca (Beng Sim Po Cam o Rico espejo del buen corazón), medtem ko za prvi prevod odlomkov Konfucijevih misli v španščino velja delo iz leta 1676 Zgodovinske, politične in moralne razprave o kitajski monarhiji (Tratados históricos, políticos y morales de la monarquía de China), ki vključuje obsežne prevode besedil klasične kitajske filozofije, med njimi tudi fragmente Konfucijeve misli, prevedel pa ga je Fray Domingo Fernández de Navarrete (Torres Trimállez, 2014). ${ }^{29}$

Splošno gledano se je Konfucijevo ime v latinskoameriških intelektualnih krogih začelo vidneje uveljavljati konec 19. stoletja in v 20. stoletju. V Braziliji je bil na primer leta 1873 v Rio de Janeiru ustanovljen duhovni center »Konfucijeva skupina», kar je bilo v skladu s fascinacijo z vsem vzhodnim, ki je v Latinski Ameriki vzniknila v 19. stoletju (Bueno, 2015, 114). Skupina intelektualcev se je sicer navdihovala pri starem kitajskem mojstru, vendar pa ga je očitno prebirala $v$ latinščini, francoščini in angleščini, ker, presenetljivo, $\mathrm{v}$ tistih časih ni prišlo do prevoda Konfucijevih del v portugalščino.

V nadaljevanju predstavimo nekatere najpomembnejše prevode del, neposredno ali posredno povezanih s Konfucijem in konfucianizmom, $\mathrm{v}$ španščino in portugalščino, ki po našem mnenju igrajo pomembno vlogo pri razvoju latinskoameriških sinoloških študij v 20. stoletju. Omejujemo se na dela, izdana pri latinskoameriških založbah

28 Za več informacij o prevodih tako klasičnih kot sodobnih kitajskih del v španščino glej izčrpno spletno stran http://china-traducida.net/ [6. 3. 2016], kjer lahko med drugim preberemo, da je verjetno najboljši prevod Konfucija v španščini izšel leta 1997 pri založbi Kairós v Barceloni (Lun Yu. Reflexiones y enseñanzas, prevedla, opombe in spremno besedo napisala Anne-Hélene Suárez).

29 Za prvi integralni prevod Konfucija neposredno iz kitajščine pa velja latinski prevod skupine jezuitov iz leta 1687 z naslovom Confucius Sinarum Philosophus (García-Noblejas, G., 2010). 
(če bi vključili vse prevode v španščino in portugalščino, ki so izšli v Španiji, na Portugalskem in drugod, ${ }^{30}$ bi bilo poglavje seveda mnogo daljše oziroma bi morali napisati dodatno raziskavo).

V Braziliji se religiozni pogled na Konfucija začrta že v prvih fragmentarnih prevodih, najprej v Raposovem prevodu iz francoščine Konfucijeva filozofija (A Philosophia de Confúcio) ${ }^{31}$ leta 1939 in v leta 1940 izdanem prevodu iz angleščine enega izmed temeljnih del o Konfuciju Konfucijeva živa misel avtorja Alfreda Doeblina (O pensamento vivo de Confúcio). ${ }^{32}$ Delo je v španskem prevodu (El pensamiento vivo de Confucio) izšlo leta 1946, in sicer pri založbi Losada v Buenos Airesu. ${ }^{33}$ Pri pregledu prevodov v špansko govorečih državah Latinske Amerike po številu izdanih knjig izstopata Mehika in Argentina, ki pogosto sodelujeta tudi v okviru skupnih založniških hiš (npr. Fondo de Cultura económica, Espasa-Calpe ...), v Braziliji pa kot založniški središči izstopata Rio de Janeiro in São Paulo.

Kar zadeva neposredne prevode iz kitajščine v španščino v 20. stoletju, ne moremo mimo pisateljice in prevajalke Marcele de Juan, hčerke kitajskega diplomata, ki se je rodila leta 1905 na Kubi ter živela med Pekingom in Madridom, kjer je leta 1985 tudi umrla. Sicer so njena dela izhajala predvsem v Španiji, omeniti pa velja njen prevod Zgodbe stare kitajske tradicije (Cuentos chinos de tradición antigua), ki je leta 1948 izšel pri založbi Espasa-Calpe v Buenos Airesu. Znana je tudi po prevajanju poezije (García-Noblejas, G., 2010).

V 40. letih je izšlo še nekaj publikacij, povezanih s konfucianizmom. Precej odmevno je bilo delo patra Jeana Baptista Kao Se-Tsiena z naslovom Socialna in politična filozofija konfucianizma (La filosofía social y política del confucionismo), ki je izšlo leta 1945 pri založbi Poblet v Buenos Airesu, leta 1952 pa tudi v portugalskem prevodu v Braziliji (A filosofia social e política do Confucianismo), in sicer pri založbi Ibge (São Paulo). Avtor konfucianizem predstavi kot kulturni steber kitajske civilizacije ter vključi njegove socialne in politične vidike, predvsem pa si prizadeva vzpostaviti filozofski in religijski dialog med krščanstvom in konfucianizmom $\mathrm{v}$ skladu s splošnimi latinskoameriškimi tendencami v 20. stoletju. Omeniti velja tudi delo argentinskega filozofa Juana Marina, ki je leta 1944 pri založbi Espasa-Calpe v Buenos Airesu izdal delo Kitajska: Lao Tse, Konfucij, Buda (China: Lao-Tsze, Confucio, $B u d a)$, leta 1953 pa je pri isti založbi izšlo njegovo delo, kjer že v naslovu izrazi svojo

30 Če omenimo samo že leta 1927 v Parizu izdano "Seu-Chu«. Los cuatro libros sagrados de Confucio (predgovor S. E. Tchen-Loh), ki je izšla pri založbi Franco-Ibero-Americana.

31 A Philosophia de Confúcio, Rio de Janeiro 1939 (založba Companhia Brasil).

32 O pensamento vivo de Confúcio (prevedel C. Lacerda), São Paulo 1940.

33 Podrobneje o afro-azijski bibliografiji prevodov v španščino glej De la Lama in dr. (1981). 
percepcijo Konfucija: Konfucij ali didaktični humanizem (Confucio o el humanismo didactizante). V Mehiki izide več splošnejših publikacij, posebej velja omeniti leta 1944 pri založbi Fondo de Cultura económica izdano delo več avtorjev Filosofía del Oriente (Chan Wing-Tsit in dr.), ki je prevod dela Philosophy-East and West, izdanega istega leta pri Princeton University Press (urednik Charles A. Moore), in ki je za špansko govoreče raziskovalce še vedno relevantna referenca. Tretje poglavje z naslovom "Zgodovina kitajske filozofije« (Historia de la Filosofía China, Wing-tsit, str. 64-122) podrobneje predstavi tudi izvorni konfucianizem (poleg daoizma in sofizma) ter neokonfucianizem.

Prvi integralni prevod Konfucijevega dela na latinskoameriških tleh v 20. stoletju je najprej izšel v španščini leta 1956 pri mehiški založbi Latinoamericana, in sicer z naslovom Štiri knjige o kitajski filozofiji, morali in politiki (Los cuatro libros de filosofía, moral y política de China), prevedel in spremno besedo napisal Farrán y Mayoral, leta 1974 pa še v Braziliji z naslovom Konfucijeva doktrina (A Doutrina de Confúcio) v Gebranovem prevodu iz francoščine.

Za brazilsko sinologijo sta v 50. letih ključnega pomena izida prevodov dveh del kitajskega pisatelja, jezikoslovca in prevajalca Lina Yutanga, Konfucijeva modrost ( $A$ sabedoria de Confucio, založba Olympio) ter Modrost Indije in Kitajske (Sabedoria de India e China, založba Pongueti); oba sta izšla leta 1958 v Rio de Janeiru.

V 80. in 90. letih 20. stoletja se pospešeno izdajajo različni zgodovinski in filozofski pregledi ter enciklopedije, v Mehiki na primer leta 1987 izide Kratka zgodovina kitajske filozofije (Breve Historia de la Filosofía China) avtorja Fung Yu-Lana, v Buenos Airesu pri založbi Kier pa Slovar vzhodnjaške filozofije (Diccionario de filosofía oriental), v katerem pomemben del predstavljajo tudi članki o konfucianizmu. Njegov avtor je argentinski pisatelj in novinar Samuel Wolpin, ki je na temo vzhodnoazijske filozofije objavil več kot 20 člankov in slovarjev. 80. leta v Braziliji pa zaznamuje izid prevoda dela Konfucijeve razprave (Diálogos de Confúcio) ${ }^{34}$ kitajsko-francoske sinologinje Anne Cheng (prevoda v španščino trenutno (še) ni), s katerim se brazilskemu bralstvu prvič predstavi Lunyu.

Leta 1980 so bila Konfucijeva dela v portugalščino prvič prevedena neposredno iz kitajščine - prevajalec je bil portugalski jezuit Joaquim Guerra. ${ }^{35}$ Delo je sicer izšlo v Macau, vendar so se izvodi razširili tudi po Braziliji (Bueno, 2015, 121). Glede splošnejših publikacij velja v Braziliji omeniti tudi leta 1997 izdano Granetovo delo Kitajska miselnost (O pensamento Chinês) ${ }^{36}$ ter poglavje o kitajski

34 Dialogos de Confucio, São Paulo 1983 (založba Ibrasa).

35 Guerra, J., Quadrivolume de Confúcio, Macau 1984 (založba Jesuítas Portugueses). 
filozofiji W. T. Chana v monografiji Filosofia: Oriente, Ocidente, ${ }^{37}$ ki je izšla že leta 1979 v São Paolu.

$\mathrm{V}$ 21. stoletju se publikacije in prevodi množijo, poleg tega so elektronske knjige in svetovni splet dodobra zabrisali geografske meje. Lahko pa omenimo za latinskoameriško sinologijo pomemben izid dveh prevodov, in sicer dela Pristni Konfucij (O Autêntico Confúcio) avtorice Annping Chin iz leta 2008 (v španščini je delo izšlo leta 2009 pri barcelonski založbi Península) ter dela Zgodovina kitajske miselnosti (História do Pensamento Chinês) iz leta 2009 avtorice Anne Cheng (v španščini je delo izšlo leta 2002 pri barcelonski založbi Bellaterra Edicions). Prva monografija, eno izmed redkih specializiranih del o Konfuciju, je natančni pregled njegovega življenja in dela na podlagi temeljnih referenc, zato je pomemben vir za akademske in znanstvene raziskave. Druga pa je natančen pregled zgodovine kitajske misli od antike do danes ter je bistvenega pomena za slehernega sinologa in vse, ki bi radi bolje razumeli konfucianizem (Bueno, 2015, 124).

$\mathrm{Na}$ špansko govorečem področju velja omeniti še argentinskega pisatelja in prevajalca iz kitajščine, filozofa in zgodovinarja Alfonsa Arauja, ${ }^{38}$ ki živi in deluje na Kitajskem. Pri argentinski založbi Quadrata ${ }^{39}$ sta leta 2013 izšla dva njegova prevoda klasičnih konfucijancev: Knjiga obredov. Klasična konfucijanska etika in vrednote (El libro de los ritos. El clásico confuciano de la ética y los valores, avtorji Dai De, Dai Sheng, Ma Rong in Zheng Xuan) ter Pomladne in jesenske kronike. Pripovedi o konfucianizmu (Crónicas de primavera y otoño. Relatos de confucianismo, avtor Yuo Qiuming).

\subsection{Znanstveni članki in monografske publikacije}

Kar zadeva znanstvene študije $\mathrm{v}$ španskem jeziku o konfucianizmu in novem konfucianizmu v drugi polovici 20. in v začetku 21. stoletja v Latinski Ameriki, je gotovo najbolj reprezentativen arhiv izdaj založbe El Colegio de México, tako knjižnih publikacij kot že omenjene znanstvene revije Estudios de Asia y África, ki se ponaša z več kot petdesetletno tradicijo delovanja.

Spletni katalog publikacij v povezavi s Kitajsko v letih 2006-2014 vsebuje 15 znanstvenih monografij. Med njimi velja izpostaviti naslednje: Chen Yong, ¿Es el confucianismo una religión? (predstavimo jo podrobneje v naslednjem poglavju), dve monografiji o kitajski zgodovini že omenjene mehiške sinologinje Flore Botton Beja,

37 Chan, W. T., Historia da Filosofia Chinesa, Filosofia: Oriente, Ocidente, São Paulo 1979 (založba EDUSP-Cultrix).

38 Araujo je tudi eden izmed ustanoviteljev že omenjenega centra za mehiško-kitajske študije na univerzi Autónoma v Mehiki.

39 Založba, pri kateri izdajajo predvsem filozofska dela, je bila ustanovljena leta 2004. 
zbornik $^{40}$ znanstvenih člankov o kitajski tematiki, ki so izhajali v reviji Estudios de Asia y África, ter splošno monografsko publikacijo o Kitajski z naslovom Kitajska. Študije in eseji v čast Flori Botton Beja (China. Estudios y ensayos en honor a Flora Botton Beja $)^{41}$ kot poklon profesorici Flori Botton ter njeni vlogi pri oblikovanju in uveljavljanju mehiške in latinskoameriške sinologije, ko je v 60. in 70. letih prejšnjega stoletja orala ledino. $^{42}$

Spletni brskalnik revije Estudios de Asia y África nam o Konfuciju in konfucianizmu ponudi naslednje zadetke: o Konfuciju en izvirni znanstveni članek iz leta 1967 »Reči orient, od Konfucija do Maoja« (El Oriente Rojo, de Confucio a Mao), ${ }^{43} \mathrm{ki}$ je prevod članka znanega francoskega sinologa Leona Vandermeerscha, o konfucianizmu pa 17 zadetkov, od tega je sedem recenzij in deset izvirnih znanstvenih člankov. Najstarejši iz leta 1990 se ukvarja $\mathrm{z}$ odnosom med konfucianizmom in modernizacijo na Tajvanu (Relación entre confucianismo y modernización, el caso de Taiwan), ${ }^{44}$ avtor je Carl T. Berrisford. Zgodovinarka Elisabetta Corsi v članku iz leta 1997 raziskuje tradicijo in eksegezo v obdobju Han (Por amor a los clásicos, tradición y exégesis en la China del periodo Han) ${ }^{45}$ Romer Cornejo Bustamante proučuje konfucianizem in gospodarski razvoj (Confucianismo y desarrollo económico), ${ }^{46}$ José Antonio Jiménez se ukvarja s pomenom in posledicami interpretacije konfucianizma s strani jezuita Mattea Riccija (La interpretación ricciana del confucianismo), ${ }^{47}$ medtem ko filozofinja Isabelle Duceux primerja eksegetske prakse na Kitajskem in v Evropi na primerih neokonfucianizma in neoplatonizma (Las prácticas exegéticas en China y Europa, neoconfucianismo y neoplatonismo). ${ }^{48}$ Španski raziskovalec César Guarde-Paz, ki je iz kitajske filozofije doktoriral na univerzi v Barceloni in predava na univerzi Nankai v Tianjinu, je avtor dveh člankov, ${ }^{49}$ ki raziskujeta razsvetljensko interpretacijo konfucianizma $\mathrm{z}$ evropske perspektive.

40 Cornejo (ur.), China: perspectivas sobre su cultura e historia, dos tomos, Mehika 2006.

41 Cornejo (ur.), Mehika 2012.

42 In tako začela uresničevati to, o čemer sta že leta 1961 pisala Fairbank in Lidbeck, da Latinska Amerika nujno potrebuje vpeljavo kitajskih študij (Cornejo, 2012, 15).

43 Estudios orientales, 2/2 (4) (1967), str. 103-117.

44 Estudios de Asia y África, 25/2 (82) (mayo-ago. 1990), str. 287-308.

45 Estudios de Asia y África, 32/3 (104) (sept.-dic. 1997), str. 625-632.

46 Estudios de Asia y África, 32/3 (104) (sept.-dic. 1997), str. 519-538.

47 Estudios de Asia y África, 37/2 (118) (mayo-ago. 2002), str. 211-239.

48 Estudios de Asia y África, 40/3 (128) (sept.-dic. 2005), str. 539-575.

49 »Texto y arte en la formación de la interpretación ilustrada del confucianismo«, Estudios de Asia y África, 48/1 (150) (ene.-abr. 2013), str. 171-201; »La lectura ilustrada europea del confucianismo, entre Malebranche y Voltaire«, Estudios de Asia y África, 48/2 (151) (mayo-ago. 2013), str. 327-355. 
In ne nazadnje, avtor treh člankov o konfucianizmu v reviji Estudios de Asia y África je kitajski filozof in religiolog Chen Yong, ki je doktoriral na Univerzi Vanderbilt v ZDA, njegova matična ustanova pa je El Colegio de México. V prvih dveh člankih ${ }^{50}$ se ukvarja s polemiko o (ne)religioznosti konfucianizma (ki je avtorjevo osrednje raziskovalno področje, zato ga podrobneje predstavimo $\mathrm{v}$ naslednjem poglavju), medtem ko članek iz leta $2015 \mathrm{z}$ naslovom »Nedavni preporod ljudskega konfucianizma na Kitajskem: ponovno odkritje klasičnih konfucijancev, akademij in ritualov« (El reciente resurgimiento del confucianismo popular en China Continental: el redescubrimiento de los confucianistas clásicos, las academias y los ritos) ${ }^{51}$ proučuje nedavna konfucijanska gibanja na Kitajskem in izpostavi tri vidike: kampanjo in promocijo recitiranja klasičnih konfucijancev, preporod konfucijanskih akademij in obujanje konfucijanskih obredov. Dotakne se tudi fenomena Jiang Qinga, t. i. fundamentalističnega konfucijanca kot domnevno osrednje figure, ki stoji za vsemi konfucijanskimi gibanji. V okviru teorij verskega fundamentalizma (Wallace, Stark) avtor pokaže, da so družbeno-politične in kulturne razmere sodobne kitajske države omogočile vzpon tradicionalističnih gibanj (tudi konfucianizma) ter da je kombinacija Jiangove fundamentalistične filozofije in njegove stroge moralne samodiscipline konfucijansko iniciativo obarvala s t. i. religiozno iskrenostjo (Chen, 2015, 44).

$\mathrm{Na}$ koncu lahko omenimo še dve nedavno objavljeni študiji, ki konfucianizem obravnavata znotraj sodobnih tem: v reviji MEC-EDUPOAZ univerze Autónoma v Mehiki je lani izšel članek z naslovom »Konfucij: Jezik in dejanje. Dialog med Vzhodom in Zahodom" (Confucio: Lenguaje y Acción. Diálogo entre Oriente y Occidente), ${ }^{52} \mathrm{v}$ reviji za mednarodne odnose iste univerze pa prevod angleškega članka o konfucianizmu in kitajsko-korejskih odnosih Johna B. Duncana, profesorja na kalifornijski univerzi v Los Angelesu, »Konfucianizem: Davčni sistem in kitajskokorejski odnosi« (Confucianismo: el sistema tributario y las relaciones sino-coreanas). ${ }^{53}$

\subsection{Refleksije o opredelitvi konfucianizma kot religije (Yong Chen)}

Ko govorimo o aktualnih konfucijanskih študijah v Latinski Ameriki, ne moremo mimo dela že omenjenega filozofa in religiologa Chen Yonga, ki sicer izvorno piše $\mathrm{v}$ angleščini, izvirne znanstvene članke in študije pa objavlja tudi v španščini, saj

50 "El resurgimiento de la controversia en torno a la religiosidad confuciana en China «, Estudios de Asia y África, 45/2 (142) (mayo-ago. 2010), str. 293-321; »Algunas reflexiones metodológicas en torno de la definición del confucianismo como religión«, Estudios de Asia y África, 47/3 (149) (sept.-dic. 2012), str. 453-483.

51 Estudios de Asia y África, 50/1 (156) (ene-abr. 2015), str. 43-75.

52 Mota Bello, G., Antonio Islas, R., MEC-EDUPAZ, 2, 2015, str. 549-587.

53 Duncan, J., Revista de Relaciones Internacionales de la UNAM, 103, str. 155-167. 
deluje pod okriljem El Colegio de México, kjer tudi predava. Chen meni, da je treba za razumevanje novih konfucijanskih gibanj najprej razumeti ambivalentnost konfucianizma v povezavi z religijo. O tej temi je objavil več študij, tudi monografsko publikacijo, najprej v španščini pri El Colegio de México leta 2012, z naslovom Je konfucianizem religija? Polemika o konfucijanski religioznosti, njen pomen in posledice (¿Es el confucianismo una religión? La controversia sobre la religiosidad confuciana, su significado y trascendencia), leto kasneje pa je delo s podobno tematiko pri založbi Leiden y Boston izšlo še v angleščini - Konfucianizem kot religija: kontroverze in posledice (Confucianism as Religion: Controversies and Consequences, 2013). Gre za avtorjevo osrednje raziskovalno področje, iz katerega je tudi doktoriral.

Pri španski, torej prvi knjigi najprej pritegne pozornost zasnova naslova kot vprašanja, saj bralec (upravičeno?) pričakuje, da delo ponudi tak ali drugačen odgovor, da se torej vprašanje razreši. Očitno pa je, da je preprostost vprašanja le navidezna, saj gre za eno osrednjih dilem tako vzhodnih kot zahodnih sinologov in religiologov. Avtorjevo prvo vprašanje, je konfucianizem religija?, vodi k drugemu, verjetno še pomembnejšemu: je možna formulacija tega vprašanja $v$ kitajščini ${ }^{54}$ Chen že na začetku izpostavi, da gre pri obeh vprašanjih predvsem za problem konceptualizacije fenomena religije, ki v tem primeru zadeva tako etimološki razvoj besede v intelektualni zgodovini Zahoda kot tudi popolno odsotnost te besede v kitajskem besedišču pred moderno dobo. S terminologijo pa se zaplete že pri jezikovni dvoumnosti terminov rujia 儒家, rujiao 儒教 in ruxue 儒学, saj nobeden izmed njih ne ponuja dovolj celovite ustreznice, ki bi bila primerljiva s terminom »konfucianizem $",{ }^{55}$ kot so ga uvedli jezuiti, da bi kitajski misli lahko približali krščanstvo $(2012,70)$. Oba izraza, »konfucianizem « in »religija«, sta del zahodne terminologije, zato se nujno zaplete pri njuni vključitvi $\mathrm{v}$ kitajski sistem, še posebej kar zadeva prehod iz tradicionalne v moderno družbo. Avtorja zato zanima predvsem način, kako se določen na videz religiozni pojav povezuje $\mathrm{z}$ miselnimi temelji moderne Kitajske $(2012,16)$. Analizo razvije skozi tri zgodovinska obdobja: prihod jezuitov (s katerimi se po njegovem mnenju začne resnična kontroverznost vprašanja (ne)religioznosti konfucianizma), obdobje zadnjih let 19 . in prvih let 20. stoletja, ko s koncem imperializma v kitajski prostor vstopi moderno mišljenje zahoda (izpostavi poskus Kang Youweia, da bi konfucianizem postal državna religija, in antikonfucianizem četrtomajskega gibanja), tretje obdobje pa so 70. leta, predvsem leto 1978, ki ga zaznamuje Ren Jiyev predlog interpretacije konfucianizma kot religije, kar sproži številne ugovore, predvsem sociologov. Avtor v svoji natančni

54 Kanadski primerjalni religiolog Wilfred C. Smith je bil prepričan, da je to vprašanje, na katero Zahod nikoli ni bil sposoben odgovoriti, Kitajska pa si ga ni bila sposobna postaviti (Smith, 1998).

55 Velja omeniti, da se je v slovenski sinologiji uveljavilo razlikovanje med konfucijanstvom, kot ustreznico za izraza rujia in ruxue (izvorni nauk in njegovi filozofski razvoji) ter konfucianizmom, rujiao, ki označuje državno doktrino in državotvorno ideologijo, ki je na Kitajskem in v vsej Vzhodni Aziji prevladovala od 2. do začetka 20. stoletja. 
epistemološki analizi razmišlja o imperialnih praksah in njihovi samoumevni oznaki kot konfucijanskih ter hkrati to samoumevnost postavlja pod vprašaj (eno od vprašanj zadeva, na primer, tian 天, ${ }^{56}$ shangdi 上帝 ${ }^{57}$ ter vero v duhovna bitja, ki so znotraj t. i. novega konfucianizma predstavljene kot tradicionalne vrednote, konfucianizem pa je posledično interpretiran kot etično-religiozni sistem).

Opredelitev konfucianizma znotraj kategorije religije torej zahteva hkratno reformulacijo obeh pojmov. Poleg problematičnosti samega termina »konfucianizem « in njegove (ne)religioznosti pa Chen opozori, da tudi pojem »religija« (v kitajščini zongjiao 宗教) z družbenimi spremembami variira. Spomni na t. i »pragmatični obrat « konec 60. in na začetku 70. let, ko se skrha gotovost univerzalizma in esencializma ter se pojavijo koncepti »metodološkega agnosticizma« in »metafizične nevtralnosti« (Platvoet), »kulturne intuitivnosti« (Melford Spiro) ter teoretska zavrnitev izraza »religija« (W. C. Smith, T. Fitzgerald). Avtor se zaveda, da je religiozno izražanje na Kitajskem specifično ter da ga je težko spraviti v okvire tradicionalnih institucij, kot so konfucianizem, budizem in daoizem, zato zanje predlaga t. i. »minimalno definicijo « in jih opredeli kot specifične spektre tradicionalne kitajske družbe, ki imajo svoj kanon pravil in načel, posebej izučeno osebje ter institucionalno infrastrukturo (2012, 125). Razvidna je avtorjeva težnja, da bi presegel sinkretičnost kitajskega religioznega prostora ter tako dosegel globlji uvid v značilnosti religioznih institucij, kljub temu pa mora zaključiti, da v tradicionalni kitajski družbi ni vidnih razlik med institucionalnimi tradicijami in ljudsko religijo ter da se sinkretizem na Kitajskem pojavlja na vseh družbenih področjih. Hkrati ugotavlja, da je diskurz, v katerem se postavlja vprašanje, ali je konfucianizem religija, konstrukt, analiza mora namreč izhajati iz epistemoloških parametrov, znotraj katerih je družbeno-kulturni pomen tudi besedilen in s pomočjo katerih se lahko koncepti medkulturno prenesejo v kitajsko besedišče $(2012,113)$. Diskusija o (ne)religioznosti konfucianizma tako po eni strani temelji na priznavanju posebnosti kitajske tradicije, na drugi strani pa implicira, da je treba za njeno izpeljavo prevzeti zahodne kategorije. Avtor pa pokaže še na eno dvojnost tega »modernega problema«, kjer je treba soočiti na eni strani razumevanje kitajske modernizacije, na drugi pa razumevanje moderne družbe s kitajske perspektive $(2012,183)$. V skladu s slednjim kitajska vlada poskuša vzpostaviti diskurz, s katerim bi ponovno utrdila kitajsko nacionalno podobo (kot na primer poskus Hu Jintaoja k vrnitvi k marksistični misli in maoistični, s konfucijanskimi vrednotami omiljeni ideologiji), kar pa je treba po avtorjevem mnenju ločiti od analize pragmatičnega koncepta religije. Poudari, da je treba modernost s kitajske perspektive obravnavati v skladu s splošno človeško naravo in kulturno identiteto, predvsem kot odgovor na izzive moderne družbe, ne pa

56 Koncept Neba ali narave.

57 Koncept vrhovnega vladarja ali Boga. 
$\mathrm{v}$ povezavi z nacionalističnim diskurzom $(2012,214)$. Zdi se, da novi konfucianizem ne uspe preseči razlike med tradicijo in modernostjo, zato Chen pričakuje, da bo pragmatična koncepcija tista, ki bo omogočila medkulturno razumevanje diskusije o konfucijanski religioznosti v modernem kitajskem kontekstu. Na koncu velja še poudariti, da Chenovo delo ni zgolj knjiga o konfucianizmu, temveč predvsem o Kitajski, o njeni tradiciji in modernosti, percepciji in avtopercepciji ter njeni identiteti - in tudi zato je po našem mnenju bistvenega pomena za razumevanje konfucianizma v latinskoameriškem prostoru. ${ }^{58}$

\subsection{Sodobni konfucianizem kot politična, filozofska in družbena opcija za prihodnost (André Bueno)}

Omenili smo že odsotnost trdne sinološke tradicije $\mathrm{v}$ Braziliji v primerjavi z drugimi Latinskoameriškimi državami, zato je logično predvidevati, da se tudi zanimanje za konfucijanske študije tu šele prebuja, prav tako proučevanje novega konfucianizma. Brazilski zgodovinar in filozof André Bueno $(2015,114)$ ugotavlja, da brazilske univerze razvoj kitajske misli slabo poznajo tudi zato, ker Konfucija še vedno vidijo predvsem kot religiozno figuro, kar naj bi bila pravzaprav splošna značilnost interpretacije vsega, kar je brazilski kulturi tuje. Možnost za spremembo vidi predvsem v prvi generaciji strokovnjakov za kitajski jezik, ki so se izobraževali na Konfucijevih inštitutih, saj so po njegovem mnenju tisti, ki bi lahko v Braziliji zbudili zanimanje tudi za novi konfucianizem in spremembe, ki se na Kitajskem obetajo v prihodnje (Bueno, 2015, 126).

Bueno je tudi sicer eden redkih brazilskih raziskovalcev, ki se ukvarja tako s konfucianizmom kot $\mathrm{z}$ novim konfucianizmom. Objavil je številne sinološke študije $\mathrm{v}$ portugalščini, angleščini in španščini v več znanstvenih in strokovnih revijah, medtem ko lahko v pričujoči številki te revije njegov članek prvič beremo tudi v slovenščini. Posebej velja omeniti njegov spletni portal www.orientalismo.blogspot.com, na kateri v okviru projekta Orientalismo od leta 2000 omogoča dostop do klasičnih kitajskih besedil in virov $\mathrm{v}$ portugalskem jeziku ${ }^{59}-\mathrm{v}$ portugalščino jih je veliko prevedel sam (zbirka obsega tako odlomke kot, v manjši meri, integralna besedila, med slednjimi so npr. Konfucijeve Razprave).

Izmed njegovih številnih študij omenjamo samo najaktualnejše, ki se osredotočajo na konfucianizem in sodobni konfucianizem, na primer »Razumeti ,novi

58 Kjer je konfucianizem še vedno hitro opredeljen kot religija, kot npr. v študiji argentinske raziskovalne skupine za Vzhodno Azijo Fakultete za družbene vede Univerze v Buenos Airesu: Arnaiz, C., Confucianismo, Budismo y la conformación de valores en China y Corea, Buenos Aires 2014. 
konfucianizem: možen prehod od marksizma h konfucianizmu v sodobni kitajski družbi« (Compreendendo o "Novo Confucionismo«: a possível transição do marxismo para o confucionismo na China Contemporânea), ${ }^{60}$ kjer analizira pojave, ki kažejo na vračanje konfucianizma kot politične in filozofske doktrine v sodobno kitajsko družbo, ter implikacije, ki jih bo imel t. i. sodobni konfucianizem pri uveljavljanju sprememb $\mathrm{v}$ sistemu kitajske politične ureditve. Istega leta v filozofski reviji objavi študijo »Novi konfucianizem« (O Novo Confucionismo $){ }^{61} \mathrm{v}$ kateri predstavi zgodovinski pregled od izvornega konfucijanstva do nastanka novega konfucianizma, tudi kot nove politične opcije v 21. stoletju. Leta 2013 objavljena študija »Duhovnik, ki je spreobrnil Konfucija«(O Padre que converteu Confúcio) ${ }^{62}$ se posveča prizadevanju portugalskega jezuita Joaquima Guerre, odličnega poznavalca kitajskega jezika in prevajalca Konfucijevih del v portugalščino, da bi dokazal, da je bil Konfucij pravzaprav eden izmed krščanskih prerokov, saj naj bi »Konfucij poučeval tako kot Kristus (...) prišel oznanjat Boga ${ }^{63}$ (Guerra, 1984). Lani izdana študija $\mathrm{z}$ naslovom »Konfucianizem in krščanstvo v Qufuju: spopad ali kulturna raznolikost? «(Confucionismo e Cristianismo em Qufu: embate ou diversidade cultural?) ${ }^{64}$ analizira poskus gradnje krščanske cerkve leta 2010 v mestu Qufu, Konfucijevem rojstnem kraju, ter njegove posledice, ki po avtorjevem mnenju kažejo na možnost nastanka novega konflikta med krščanstvom in konfucijanstvom ter postavljajo pod vprašaj možnost medkulturnega dialoga v kitajski družbi. Trenutno se Bueno ukvarja predvsem s problemom (odsotnosti) recepcije Konfucija v Braziliji. Pred kratkim je izšla njegova študija »Konfucij v Braziliji: epistemološki (in zgodovinski) problem « (Confucius in Brazil: an epistemological (and historical) problem) ${ }^{65} \mathrm{v}$ kateri pretrese osrednje probleme, povezane $\mathrm{z}$ razmeroma slabo zastopanostjo konfucijanskih študij $\mathrm{v}$ Braziliji, ter predstavi najpomembnejše publikacije, povezane s Konfucijem, v zadnjih desetletjih.

Leta 2014 je Bueno souredil tudi prvo brazilsko monografijo o starodavni Kitajski z naslovom Stara branja. Pogledi na starodavno Kitajsko (Antigas Leituras. Visões da China Antiga), ki je za brazilsko sinologijo nedvomno izjemnega pomena. $\mathrm{V}$ monografiji sta objavljena dva njegova prispevka, naslov prvega je »Sinologija in konfucianizem: pomembnost konfucijskih študij za razumevanje kitajske civilizacije» (Sinologia e Confucionismo: a importância dos estudos confucionistas para a

60 Mundo Antigo, 2012a, 1, str. 127-138.

61 Filosofia (São Paulo), 2012b, 68, str. 62-72.

62 História Viva (São Paulo), 2013, 1, str. 24-29.

63 »Confúcio ensinava como Cristo [...] veio anunciar Deus« (Guerra, 1984).

64 Jiexi Zhongguo, 2015, 17, str. 4-10.

65 Contemporary East Asia and the Confucian Revival, Cambridge 2015, str. 113-128. 
compreensão da civilização chinesa), ${ }^{66} \mathrm{v}$ katerem izpostavi pomembnost poznavanja kitajske zgodovine, ki je bilo $\mathrm{v}$ Braziliji do nedavnega povsem zapostavljeno, ter postavi Konfucija v središče te zgodbe. V drugem prispevku »Kitajska misel v času Dinastije Han« (O pensamento chinês durante a Dinastia Han $)^{67}$ predstavi pregled najrelevantnejših vidikov kitajske filozofije v obdobju Dinastije Han.

\section{Zaključek}

Dejstvo je, da je v 21. stoletju v Latinski Ameriki mogoče zaznati intenzivno krepitev potrebe po proučevanju in raziskovanju tako Kitajske kot njenega jezika, kulture, zgodovine, filozofije, gospodarstva in politike, kar ugotavljajo tako ekonomisti, sociologi in politologi (npr. Shambaugh, 2013) kot tudi zgodovinarji, filozofi in jezikoslovci (npr. Arsovska, 2015). Konfucijevi inštituti, ki v zadnjem desetletju v Latinski Ameriki rastejo kot gobe po dežju, nedvomno igrajo pomembno vlogo tudi pri razvoju znanstveno-raziskovalnega elana in umeščanju sinoloških študij v latinskoameriški prostor. Pri širitvi zanimanja za konfucianizem in moderno konfucijanstvo v Latinski Ameriki bo gotovo pomemben dejavnik tudi vse pogostejše povezovanje v t. i. iberoameriške okvire ter odpiranje prostora sinološkima tradicijama Španije in Portugalske. Sporazumevanje in medsebojno razumevanje med različnimi družbenimi realnostmi zahteva določene strategije, ki temeljijo predvsem na iskanju dialoga, posebej učinkovit naj bi bil ravno filozofski (Jullien, 2014), kar dokazuje široko polje izmenjav, ki ga je sprožilo srečanje kitajske filozofije z evropsko tradicijo. Zato verjamemo, da se bo $\mathrm{v}$ prihodnosti prostor zanj razširil tudi $\mathrm{v}$ tistih delih Latinske Amerike, kjer se trenutno šele začenja. Povzamemo lahko, da je v sodobnih latinskoameriških, čeprav maloštevilnih raziskavah konfucijanstva mogoče zaznati prizadevanje za boljše poznavanje obojega, tako antične kot sodobne kitajske kulture, ter zavedanje, da sta razmislek o preteklosti ter vzpostavljanje medkulturnega dialoga $\mathrm{Z}$ »drugim« bistvena tudi za prenovo lastnih idejnih in družbenih tradicij. Kot je pravil že sam mojster: »Preučuj preteklost, kadar ugibaš o prihodnosti.«

Na koncu moramo poudariti, da je pričujoča študija neizogibno fragmentarnega značaja, saj njen namen ni in ne more biti predstavitev vseh razpoložljivih virov o konfucianizmu in novem konfucianizmu v Latinski Ameriki, temveč predvsem orisati splošni okvir položaja tamkajšnje sinologije ter osvetliti osrednje sodobne smernice, ki se ozirajo v prihodnost. To pa bo, kot trdno verjamemo, vsekakor vredno nadaljnjega raziskovanja.

66 Antigas Leituras. Visões da China Antiga, 2014, str. 56-73.

67 Antigas Leituras. Visões da China Antiga, 2014, str. 177-199. 


\section{Literatura}

Arsovska, L. (ur.), América Latina y el Caribe y China. Historia, cultura y aprendizaje del chino, Ciudad de México 2015.

Bueno, A., Compreendendo o 'Novo Confucionismo': a possível transição do marxismo para o confucionismo na China Contemporânea, Mundo Antigo, 1, 2012a, str. 127-138.

Bueno, A., O Novo Confucionismo, Filosofia (São Paulo), 68, 2012b, str. 62-72.

Bueno, A., Neto, J. M. (ur.), Antigas Leituras. Visões da China Antiga, União da Vitória 2014.

Bueno, A., Confucius in Brazil: An Epistemological (and Historical) problem, v: Contemporary East Asia and the Confucian Revival (ur. Rošker, J., Visočnik, N.), Cambridge 2015, str. 113-128.

Chen, Y., ¿Es el confucianismo una religion? La controversia sobre la religiosidad confuciana, su significado y trascendencia, Ciudad de México 2012.

Chen, Y., Algunas reflexiones metodológicas en torno dela definición del confucianismo como religión, Estudios de Asia y Africa, 47/3 (sept.-dic. 2012), str. 453-483.

Chen, Y., Confucianism as Religion: Controversies and Consequences, Leiden, Boston 2013.

Chen, Y., El reciente resurgimiento del confucianismo popular en China continental: el redescubrimiento de los confucianistas clasicos, las academias y los ritos, Estudios de Asia y África, 50/1 (ene-abr. 2015), str. 43-75.

Chen Apuy Espinosa, H., Los estudios orientales en la Universidad de Costa Rica, Estudios Orientales, 8/1.21, str. 88-90.

Chen Mok, S., Bartels Villanueva, J., Martinez Esquivel, R. (ur.). Estudios sobre China desde Latinoamérica. Geopolítica, religión e inmigración, San José 2013.

Chou L. D., Los chinos en Hispanoamérica, Cuaderno de ciencias sociales 124, San José 2002.

Cornejo, R. (ur.), China. Estudios y ensayos. En honor a Flora Botton Beja, Ciudad de México 2012.

Creutzfeldt, B. (ur.), China en América Latina: Reflexiones sobre las relaciones transpacíficas, Bogotá 2012.

De la Lama, G. (ur.), Bibliografía afroasiática en español, Ciudad de México 1981.

Díaz Díaz, G., Santos Escudero, C., Bibliografía filosófica hispánica (1901-1970), Madrid 1982. 
Fairbank, J. K., Lidbeck, J. M., United States Aid to Latin America in Chinese Studies, Asian Survey, 1/9, 1961, str. 32-34.

Herrera Feligreras, A., La nueva sinología española, Huarte de San Juan. Geografía e Historia, 14, Pamplona 2008, str. 257-267.

Johnson, G. B., Lin, Z., Sino-Latin American Relations: A Comparison of Expert and Educated Youth Views of Latin America, JCIR, 3/1, 2015, str. 26-52.

Jullien, F., On the Universal: The Uniform, the Common and Dialogue between Cultures, Cambridge 2014.

Lida, C. E. in dr., La Casa de España y El Colegio de México, México 2000.

Smith, W. C., Patterns of faith around the world, Oxford 1998.

Shambaugh, D., China Goes global. The Partial Power, Oxford, New York 2013.

Shixue, J., Latin American Studies in China: An Overview, Revista del CESLA, 6, 2004, str. 277-281.

Torres Trimállez, M., Crónicas misioneras y sociedades nativas: China a fines del siglo XVII, Santander 2014.

\section{Pomembnejše spletne strani}

Akademska mreža Latinske Amerike, Karibov in Kitajske: http://www.redalc-china.org/

Center za azijske in afriške študije: http://ceaa.colmex.mx/ceaa/

Iberoameriška raziskovalna mreža za vzhodnoazijske študije: http://rediao.org/site/ index.php

Inštitut za brazilsko-kitajske študije: http://www.ibrach.org/

Konfucijanski inštituti Latinske Amerike: http://www.crical.cl/institutos/

Latinskoameriško združenje za azijske in afriške študije: http://ceaa.colmex.mx/ aladaa/

Revija za azijske in afriške študije, El Colegio de México: http://revistas.colmex.mx/ sobre-estudios-de-asia-y-africa/

Spletni portal klasičnih kitajskih besedil v portugalščini: www.orientalismo. blogspot.com 


\section{Barbara Pihler Ciglič}

\section{Od Mehike do Brazilije, od starodavne Kitajske do novega konfucianizma: sinološke študije v Latinski Ameriki}

Ključne besede: Latinska Amerika, sinologija, konfucianizem, El Colegio de México, Estudios de Asia y África, Chen Yong, André Bueno

V študiji začrtamo splošni okvir začetkov in razvoja sinoloških študij na geografsko, politično in kulturno zelo raznolikem področju Latinske Amerike ter izpostavimo osrednje sodobne vidike in tendence. V 21. stoletju se hitro rastoča povezanost med Kitajsko in Latinsko Ameriko odraža v pospešenem ustanavljanju raznolikih gospodarsko-političnih ter akademsko-izobraževalnih institucij in publikacij ter $\mathrm{v}$ organizaciji številnih mednarodnih konferenc in znanstvenih srečanj. Razvoj konfucijanskih študij najprej analiziramo s pregledom najpomembnejših prevodov in publikacij 20. stoletja v povezavi $\mathrm{z}$ »naukom izobražencev« na latinskoameriških tleh ter s preglednim komentarjem najodmevnejših znanstvenih člankov in monografij. Nato se študija osredotoči na Mehiko, državo z najdaljšo sinološko tradicijo v Latinski Ameriki, kjer Centro de Estudios de Asia y África na El Colegio de México še danes velja za eno najuglednejših latinskoameriških središč za azijske in afriške študije. Zatem se posveti Braziliji, za katero se zdi, da ima od vseh držav najmanj trdno tradicijo proučevanja sinoloških in konfucijanskih vsebin. Osrednje premise sinoloških in konfucijanskih raziskav $\mathrm{v}$ teh dveh deželah predstavimo skozi prizmo študij dveh pomembnih sodobnih sinologov, Chen Yonga (El Colegio de México) in Andréja Buena (Universidade do Estado Rio de Janeiro). 
Barbara Pihler Ciglič

\section{From Mexico to Brazil, from Ancient China to New Confucianism: Sinological Studies in Latin America}

Keywords: Latin America, Sinology, Confucianism, El Colegio de México, Estudios de Asia y África, Chen Yong, André Bueno

The paper presents a general framework of the beginnings and development of sinological studies in geographically, politically and culturally very diverse Latin America, and highlights current issues and trends therein. In the $21^{\text {st }}$ century the fastgrowing relationship between China and Latin America is reflected in the accelerated creation of diverse economic-political, academic and educational institutions, publications and in the organization of numerous international conferences and scientific symposia. The study analyses the development of Confucian Studies first, through reviewing the most important translations and publications of the $20^{\text {th }}$ century in connection with "the intellectual movement" in Latin America, and, second, through an illustrative commentary on the most renowned scientific articles and monographs.

The study initially focuses on Mexico, the country with the longest sinological tradition in Latin America, where the Centro de Estudios de Asia y África at El Colegio de México is still regarded to be one of the most prominent Latin American centres for Asian and African Studies. The focus then shifts to Brazil, which seems, of all the countries in Latin America, to have the least well-established tradition in Chinese studies and Confucianism. The central premise of sinological and Confucian studies in these two countries is presented through the prism of major studies of two modern sinologists, Chen Yong (El Colegio de México) and André Bueno (Universidade do Estado de Rio de Janeiro). 